\title{
RBEP
}

\section{Educação escolar indígena e inclusão: por uma pedagogia do cuidado e da escuta}

Valdo Hermes de Lima Barcelos

Sandra Maders

\section{Resumo}

Uma maneira de começarmos um texto sobre a educação escolar indígena no Brasil é lembrando que, quando aqui chegaram os navegadores portugueses, nos idos de 1500, esse território era habitado por cerca de mil povos diferentes - transcorridos cerca de 500 anos, restam não mais de 200. Mesmo assim, a grande maioria dos brasileiros não sabe que são faladas cerca de 180 línguas diferentes. Este texto resulta de um conjunto de pesquisas sobre a situação da educação escolar indígena e tem como um de seus objetivos explicitar as contribuições de algumas proposições epistemológicas de Humberto Maturana para a edificação de uma educação junto às comunidades indígenas que promova a inclusão social e cultural. Nossas pesquisas têm demonstrado que, para que essa educação escolar indígena aconteça de forma inclusiva, há que se atentar para emoções como o cuidado, a escuta e o acolhimento das diferenças no espaço escolar numa perspectiva de diálogo intercultural.

Palavras-chave: educação indígena; Humberto Maturana; educação e inclusão. 


\title{
Abstract \\ Indigenous education and social inclusion - for pedagogy of care and attentiveness
}

A way for us to start a text about indigenous education in Brazil is remembering that when the Portuguese navigators came here in the 1500s, this territory was inhabited by about a thousand of different peoples. After about 500 years, there were no more than 200. Still, the majority of brazilians don't know that there are about 180 different spoken languages. This text is the result of a set of researches about the situation of indigenous education and has, as one of its goals, to make explicit the some of the Humberto Maturana's epistemological proposals for the edification of education within the indigenous communities, proposals that will promote their social and cultural inclusion. Our researches have shown that, in order for the indigenous education to take place in an inclusive way, one have to pay attention to emotions such as care, listening and the welcoming of differences within the school space for an intercultural perspective of dialog.

Keywords: indigenous education; Humberto Maturana; education and inclusion.

\section{Mil povos}

\begin{abstract}
A escola veio, se instalou no nosso meio e não pediu licença. Nós, como professores indígenas, temos que mudar essa escola, temos que garantir que ela tenha qualidade. Para isso, temos que estudar a legislação, para conhecer e conquistar novos direitos.

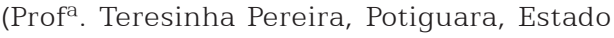
do Ceará)
\end{abstract}

Acreditamos que uma boa maneira de começarmos uma conversa, ou um texto, sobre a educação escolar indígena no Brasil é lembrando que, quando aqui chegaram os navegadores portugueses, nos idos de 1500, esse território era habitado por cerca de mil povos diferentes. Eram os nativos desta terra - chamados de "índios" pelos navegadores portugueses - que viviam livres, alegres e "soltamente", como gostava de dizer o antropólogo e estudioso dos povos nativos brasileiros Darcy Ribeiro (1922-1997). Atualmente, transcorridos cerca de 500 anos, restam não mais de 200 desses povos habitando essas terras brasilis, contudo, algo é ainda mais paradoxal: o fato de a grande maioria dos brasileiros não saber que no País ainda existem esses povos, além, é claro, 
da civilização branca ocidental, e não saber, também, que são faladas por eles cerca de 180 línguas diferentes. Esse desconhecimento não é algo apenas presente entre a grande massa da população; infelizmente, mesmo nos meios acadêmicos e intelectuais, poucos são os que sabem da existência desse ainda significativo contingente de brasileiros nativos da terra de pindorama. Portanto, uma conclusão óbvia é que a nação brasileira é formada por três grandes matrizes étnicas: a portuguesa, a africana e a tupi-guarani.

Se olharmos para nosso passado recente, últimos 500 anos, veremos que cerca de 800 povos desapareceram - foram de diferentes formas dizimados. Com eles desapareceram suas línguas, seus rituais e seus hábitos alimentares, logo, quando some uma língua, some com ela uma cultura. Não esqueçamos que esses povos não tinham escrita, sua comunicação era, basicamente, por meio da oralidade. Portanto, quando desaparece um povo com essas características é aniquilada uma civilização inteira, assim como sua arte e sua filosofia - pois essas civilizações possuíam um sistema filosófico de vida extremamente complexo e rico em contribuições para as demais formas de pensar a vida no planeta. Tanto isso é verdadeiro que são inúmeros os casos em que pesquisadores de vários países, e mesmo do Brasil, recorrem aos saberes dos povos nativos para estudarem, copiarem e transformarem em conhecimento científico, e logo em seguida em mercadoria, aquilo que é um patrimônio de saberes milenares desses povos.

Esse processo histórico, marcado por conflitos, resistências, derrotas e vitórias, levou a que se fizessem necessárias leis, normas e regras jurídicas que visam orientar as relações entre os povos indígenas e as comunidades envolventes. O sistema educacional brasileiro, como parte integrante da sociedade, não ficou fora desse processo histórico-político-cultural.

Uma rápida olhada na Lei de Diretrizes e Bases da Educação (LDB - Lei no 9.394/1996) pode mostrar-nos um conjunto de orientações que se postas em prática, mesmo com suas fragilidades, poderiam proporcionar um avanço significativo nas políticas públicas referentes à educação escolar dos povos indígenas. Vejamos o que reza a LDB, art. 26, caput e $\S 4^{\circ}$ :

Caput - Os currículos do ensino fundamental e médio devem ter uma base nacional comum, a ser complementada, em cada sistema de ensino e estabelecimento escolar, por uma parte diversificada, exigida pelas características regionais e locais da sociedade, da cultura, da economia e da clientela.

§ $4^{\circ} \mathrm{O}$ ensino da História do Brasil levará em conta as contribuições das diferentes culturas e etnias para a formação do povo brasileiro, especialmente das matrizes indígenas, africana e europeia.

A Constituição da República Federativa do Brasil de 1988, art. 231, versa sobre os direitos legais dos povos indígenas e sobre as responsabilidades da União com sua educação: 
São reconhecidos aos índios sua organização social, costumes, línguas, crenças e tradições, e os direitos originários sobre as terras que tradicionalmente ocupam, competindo à União demarcá-las, proteger e fazer respeitar todos os seus bens.

Como se pode constatar, é reconhecido e legitimado que os povos indígenas tenham assegurados seus direitos básicos de acesso à educação, com o respeito e o acolhimento de suas tradições, crenças e formas de viabilizar sua existência. Para tanto, o Estado Brasileiro deverá promover, resguardar e responsabilizar-se por:

Art. $78[\ldots]$

I - proporcionar aos índios, suas comunidades e povos, a recuperação de suas memórias históricas, a reafirmação de suas identidades étnicas, a valorização de suas línguas e ciências;

II - garantir aos índios, suas comunidades e povos, o acesso às informações, conhecimentos técnicos e científicos da sociedade nacional e demais sociedades indígenas e não-índias.

Art. 79 - A União apoiará técnica e financeiramente os sistemas de ensino no provimento da educação intercultural às comunidades indígenas, desenvolvendo programas integrados de ensino e pesquisa.

$\S 1^{\circ}$ Os programas serão planejados com audiência das comunidades indígenas.

$\S 2^{\circ}$ Os programas a que se refere este artigo, incluídos nos Planos Nacionais de Educação, terão os seguintes objetivos:

I - fortalecer as práticas socioculturais e a língua materna de cada comunidade indígena;

II - manter programas de formação de pessoal especializado, destinado à educação escolar nas comunidades indígenas;

III - desenvolver currículos e programas específicos, neles incluindo os conteúdos culturais correspondentes às respectivas comunidades; IV - elaborar e publicar sistematicamente material didático específico e diferenciado. (Brasil, 1996).

Essas rápidas referências históricas, bem como a legislação atual no que tange aos direitos e à educação escolar indígena, tiveram a intenção de explicitar, mesmo que sucintamente, o cenário em que nos encontramos hoje no Brasil em relação à atenção educacional legal dedicada a esses povos.

No próximo item, faremos uma breve apresentação das ideias de Humberto Maturana Romesín, pensador chileno, nascido em 1928, e doutor em Biologia pela Universidade Harvard, nos Estados Unidos em 1958. Em 1960, de volta ao Chile, continua seus estudos em neurobiologia. A partir da sua descrição do sistema nervoso como sistema fechado e da noção da organização autônoma dos seres vivos, começa a desenvolver a Biologia do Conhecer e a Biologia do Amar. Junto com Ximena Dávila, funda em Santiago do Chile, o Instituto de Formação Matrística, onde desenvolvem a Biologia-cultural como um modo de conhecer o nosso habitar na Matriz Biológica e Cultural da Existência Humana. Atua como docente na Universidade Metropolitana de Ciências da Educação e no 
Instituto de Terapia Familiar de Santiago, é professor convidado de várias universidades mundiais e doutor honoris causa pela Universidade Livre de Bruxelas. Por muitos, é reconhecido como um dos maiores pesquisadores atuais sobre a Biologia do Conhecimento.

A seguir, passaremos para uma reflexão sobre possíveis contribuições das proposições desse autor para pensar-se uma educação escolar indígena que se paute pela aceitação do outro, do cuidado e do respeito às suas diferenças culturais.

Nosso horizonte de reflexão se ancora, neste texto, nos referenciais epistemológicos da educação intercultural e dialógica (Fleuri, 1998; 2007); algo, na perspectiva definida por Bhabha (2003), como as relações que acontecem no espaço vivido e que o autor denomina de o entre-lugar da cultura. Um tal processo exige relações educacionais e pedagógicas que privilegiem não a oposição entre culturas, mas, sim, sua inter-relação num processo semelhante ao proposto pelo pensador William Thompson (1990) ao defender que nos tornamos humanos pela partilha e pela cooperação entre os diferentes e não pela competição e pela guerra. Essa valorização das diferenças é fundamental para que se estabeleçam relações de diálogo intercultural, pois, como defende o antropólogo inglês Gregory Bateson (1986, p. 76), para que se crie uma diferença, "são necessárias pelo menos duas coisas".

Com isso, reportamo-nos, também, ao que sugere o pesquisador contemporâneo das culturas híbridas, o argentino Nestor G. Canclini (2006; 2003), quando afirma que falar de estudos que envolvem a cultura e a educação, numa perspectiva intercultural, é falar a partir das intersecções, buscando as regiões em que as narrativas se assemelham, se opõem e se cruzam. Nossa opção pela perspectiva intercultural tem como orientação o que sugere Canclini (2004, p. 21), para o qual, "adotar uma perspectiva intercultural proporciona vantagens epistemológicas e de equilíbrio descritivo, leva a conceber as políticas das diferenças não apenas como uma necessidade de resistir". Segundo este autor, as práticas e os estudos interculturais foram fundamentais no sentido de dar aporte epistemológico para tornar visíveis os muitos grupos discriminados no continente latino-americano. Entre esses grupos discriminados historicamente, a que se refere Canclini, não podemos deixar de ressaltar os povos indígenas que são, neste texto, o principal foco de nossa reflexão.

Nesse sentido, pretendemos concentrar nossa atenção e reflexão em práticas de educação que respeitem essa cultura e de formação de educadores indígenas articuladas com movimentos socioculturais, com a intenção de encontrar dispositivos constitutivos de dialogicidade intercultural (Freire, 2002). Dialogicidade, esta, que se dá, fundamentalmente, no encontro intercultural das gentes em suas diferenças e peculiaridades étnico-culturais. Dessa relação de reciprocidade e de reconhecimento das diferenças é que poderá surgir o embrião de resistência e de desconstrução de subalternidades (Figueiredo, 2008), particularmente no âmbito das relações étnicas, que envolvem as culturas e os povos indígenas na sociedade brasileira contemporânea. 


\section{A Biologia do Amor e a Biologia do Conhecimento: ${ }^{1}$ uma referência epistemológica para a educação escolar indígena inclusiva}

\begin{abstract}
Que coisa estranha, brincar de matar índio, de matar gente. Fico a pensar aqui, mergulhado no abismo de uma profunda perplexidade, espantado diante da perversidade intolerável desses moços se desgentificando, no ambiente em que decresceram em lugar de crescer [...] Não creio na amorosidade entre os homens e as mulheres, entre os seres humanos, se não nos tornarmos capazes de amar o mundo. A ecologia ganha uma importância fundamental neste fim de século. Ela tem de estar presente em qualquer prática educativa de caráter radical, crítico ou libertador [...] Se a educação sozinha não transforma a sociedade, sem ela tampouco a sociedade muda [...] Não é possível refazer este país, democratizá-lo, humanizá-lo, torná-lo sério, com adolescentes brincando de matar gente, ofendendo a vida, destruindo o sonho, inviabilizando o amor. (Freire, 2000, p. 65-67).
\end{abstract}

\footnotetext{
${ }^{1}$ Maturana apresenta essas denominações para especificar um espaço de reflexão entendido como um domínio do nosso viver que se estabelece nas relações que participamos no conversar, como o entrelaçamento do emocionar e do linguajear. Esse espaço aparece conforme se definem na linguagem explicações e distinções sobre a experiência de definir o próprio espaço que se quer definir.

${ }^{2} \mathrm{O}$ termo "educação escolar indígena" refere-se a uma educação planejada dentro de uma determinada perspectiva curricular, com calendário escolar nacional, carga horária estabelecida e estatutos escolares, acontece em escolas regidas por estatutos, regimentos e coordenações; já o termo "educação indígena" tem a ver com a cultura de cada povo indígena e se dá durante toda a vida da criança no acompanhamento de seus pais.
}

A pesquisadora das questões relacionadas à educação escolar indígena ${ }^{2}$ no Brasil, Maria Aparecida Bergamaschi, ao analisar a importância da participação das instituições de ensino universitárias na produção de conhecimento para aprimorar as práticas de educação escolar indígena, vê na participação das universidades,

um importante projeto de futuro, que timidamente inicia o movimento para instituir, desde esse lado não-indígena da sociedade brasileira, um diálogo intercultural com os povos indígenas [...] Digo desde cá, pois os povos indígenas mostram concretamente sua disposição para isso. (Bergamaschi, 2011, p. 21).

Nessa perspectiva, há que se fazer um esforço interdisciplinar e também de diálogo com diferentes autores e pensadores. Entendemos que a educação escolar indígena, como uma modalidade de ensino, se constitui em um tema de interfaces e, como tal, há que tratá-la de forma complexa e interdisciplinar.

Uma das formas de viabilizarmos essa proposição é buscando interlocuções com autores e áreas de conhecimento que nos possibilitem diálogos e conversações que aconteçam nesses espaços de interface. Reportando-nos ao pensador da interculturalidade, Homi Bhabha, a educação escolar indígena pode ser vista como um entre-lugar de acontecimento de diálogos educativos, favorecendo, assim, a ocorrência de aprendizagens que valorizem as relações de interculturalidade e de desconstrução das relações de dominação e de imposição de subalternidades. Acreditamos que alguns desses espaços de acontecimento de relações interculturais podem ser os educativos escolares e não escolares. 
Queremos adiantar que o termo conversações é utilizado neste texto com o significado que lhe dá Humberto Maturana, ou seja, nosso ser biológico, como humanos, se constrói na imersão do ato de conversar, que é, nesse sentido, o entrelaçamento entre o racional e o emocional em um processo de linguagem comum num determinado espaço de convivência e tempo presente: o aqui e o agora. Uma das condições para que essa conversa se estabeleça é, para Maturana, a necessidade do cuidado e da escuta $^{3}$ do outro. No entanto, para que essa escuta aconteça, há que se levar em consideração, permanentemente, o entrelaçamento das emoções e das atitudes no fluir do viver cotidiano em um espaço de convivência no acolhimento, no cuidado e, principalmente, na aceitação e no reconhecimento do outro em suas diferentes formas de manifestação cultural.

As proposições do cuidado e da escuta do outro que orientam nossas reflexões, neste texto, são tributárias de dois pressupostos epistemológicos e científicos fundantes na obra de Humberto Maturana, quais sejam: a Biologia do Amor e a Biologia do Conhecimento. Essas duas proposições estão ancoradas na ideia de que a construção do conhecimento, bem como o processo de aprendizagem humana, pode se dar por diferentes metodologias e/ou práticas didáticas, metodológicas, organizativas e pedagógicas. Outro ponto importante nas proposições de Maturana que queremos ressaltar e entendemos que deve ser levado em consideração é que não existe uma separação entre aquilo que as epistemologias tradicionais chamam de dimensão biológica e dimensão cultural da pessoa e, consequentemente, nos seus processos de viver. Entre estes está a produção de conhecimento, o qual só pode ocorrer em sociedade, pois não é sensato pensar-se que possa existir qualquer tipo de sociedade humana desprovida de conhecimento. Nesse sentido, é muito pertinente o alerta feito pelo antropólogo Carlos Walter PortoGonçalves (2006, p. 117), para quem a expressão - corriqueiramente usada - sociedade do conhecimento é, no mínimo, infeliz, posto que uma sociedade sem conhecimento é mesmo

uma impossibilidade lógica, biológica e histórica. Afirmar que o conhecimento tem um papel mais importante nos dias que correm do que em outro período qualquer é (1) ignorar que o conhecimento está inscrito na vida e (2) é levar longe demais a distinção trabalho manual e trabalho intelectual, na medida em que o que observamos hoje é que um modo de produção de conhecimento que está se impondo a todos sob controle de alguns (os grandes laboratórios de pesquisa das grandes corporações transnacionais com o apoio do Estado dos países do centro hegemônico do padrão de poder mundial) [...] todavia a diversidade de culturas da humanidade é a melhor expressão da diversidade de conhecimento.

Nessa mesma linha de entendimento, sobre a relação de subalternidade imposta aos povos americanos pelos colonizadores, o escritor Silviano Santiago vai mais longe e se refere à responsabilidade da historiografia oficial e elitista nacional que, com sua visão de intelectual preguiçoso e colonizado, foi (e em muitos casos ainda é) incapaz de perceber, e ainda
${ }^{3}$ A palavra escuta aqui utilizada é intencional. Com ela queremos ressaltar a importância de, mais que ouvirmos o que o outro tem para dizer ou está dizendo, pararmos para lhe dar atenção, ou seja, dar à palavra escuta seu sentido de origem: auscultare - dar atenção ao que vem de dentro; dar espaço para a voz do interior; ouvir $o$ e com o coração e não apenas com a razão. 
de reconhecer, este passado cultural como algo a ser estudado e levado em consideração, para o entendimento e possível elaboração de uma proposta alternativa de sociedade.

Uma postura intelectual desse tipo acaba por renegar a importante e necessária contribuição das nações indígenas latino-americanas em geral, e brasileira em particular, não só para o entendimento da história mais distante, como também para compreender e dialogar de forma intercultural com aquilo que se denomina de modernidade no ocidente. Para Silviano Santiago (2000, p. 138), esse reducionismo de pensamento acaba por nos levar a

valorizar uma razão etnocêntrica, intolerante, incapaz de manter diálogo com o seu outro (culturas ameríndias e africanas), pois sempre coloca em situação hierarquicamente desfavorável e como responsável pelas piores "contaminações" que a "pureza" ocidental pode sofrer. A historiografia oficial não é capaz de perceber a contribuição cultural das raças indígenas no diálogo com a Modernidade ocidental.

Aqui queremos deixar uma primeira reflexão para pensar-se uma pedagogia e uma educação junto às comunidades indígenas que comecem por respeitar seus saberes e as práticas de viabilização de sua existência como seres no e com o mundo.

Quando pensamos a educação junto aos povos indígenas, temos que nos despir de algumas "verdades" e chavões que se tornaram "naturais" em nossa cultura ocidental moderna. Um deles é o fato de que vivemos na "sociedade do conhecimento". Ora, ao assim nos manifestar, estamos sugerindo que outras sociedades não são produtoras de conhecimento. Essa formulação está muito próxima da ideia preconceituosa e arrogante de que os povos não pertencentes à civilização ocidental eram bárbaros, sem cultura. Essa foi uma das tantas formulações, feitas pelos europeus, que se mostraram desastrosas para a vida dos povos nativos latino-americanos em geral e brasileiros em particular.

Para Maturana, a educação acontece sempre que alguma transformação ocorre em cada pessoa no fluir de seu viver cotidiano. Assim sendo, a educação - enquanto uma ação humana - será tomada como um processo que acontece em nosso viver biológico e cultural, isso significa dizer que ela ocorre em distintos espaços e tempos do viver: na família, na escola, nos locais de trabalho, de lazer, religiosos e/ou de busca de espiritualidade, etc. Nesses espaços, o ato de educar acontece como algo inerente ao nosso modo de ser e de estar no mundo, ou seja, o educar como o resultado de uma transformação na convivência com o outro e, mais, no acoplamento entre biologia e cultura.

Essa convivência não se pauta em buscar demarcar com o outro o que está certo ou errado, mas sim em conversar sobre o que queremos manter/conservar e o que queremos mudar/transformar em nossas atitudes, ou seja, propomos uma reflexão sobre nossa conduta educativa a partir do fluir do viver cotidiano. Fluir, esse, que não se distingue segundo o lugar em que a pessoa se encontra, mas em função da emoção que 
orienta suas atitudes no mundo que vive. Nesse sentido, educar não se resume a transferir conhecimentos e conteúdos, tampouco em apenas formalizá-los, e sim propor-se a uma relação pessoal cooperativa, de abertura ao novo, a partir de um emocionar específico de acolhimento que leve à aceitação mútua.

Aqui queremos adiantar que vemos uma semelhança bastante importante entre o que propõe Maturana como ato de educar e a educação indígena tradicional em seu contexto sociocultural. Como sugere Cátia Weber (2009, p. 102), "os educadores do índio têm rosto e voz, têm materiais e instrumentos, têm uma série de recursos bem definidos para educar a quem vai ser um indivíduo de uma comunidade com sua personalidade própria e não um elemento de uma multidão". Nesse sentido, vale ressaltar que a educação junto às comunidades indígenas precisa considerar que estes não abandonam suas crenças e costumes simplesmente pelo fato de estarem relacionando-se com outras culturas, como a cultura envolvente do branco.

Essa forma de pensar a educação proposta por Maturana está de acordo com uma das características muito marcantes da cultura indígena, qual seja: a inseparabilidade entre os diferentes momentos do viver. Tal forma de organizar o fluir do viver faz com que tenhamos nas sociedades indígenas uma completa integração entre a técnica, a arte e a religião, portanto, a vida acontece de forma indissociável entre a beleza e a utilidade das coisas, por exemplo, o ato de conhecer, dentro da concepção do povo Guarani, passa pelo percurso do autoconhecimento, na verdade não se separam. O corpo é um mediador na apresentação desse conhecimento - corpo nu, corpo vestido, vergonha, emoção, alegria, tristeza e alma são categorias relevantes na construção do caminho-conhecimento guarani (Bergamaschi, 2009, p. 72).

Ao estudar as origens da formação da nação brasileira, o antropólogo Darcy Ribeiro vai buscar nas artes e nas técnicas dos povos nativos exemplos de como era rica, diversificada, sofisticada e integrada a vida dos povos da floresta. Os casos trazidos por Ribeiro são inúmeros em sua extensa obra. Só para citar um exemplo na arte e outro nas técnicas produzidas, utilizadas e legadas pelos povos tupi-guaranis, o autor evidencia a criatividade dos indígenas, presente em tudo o que eles produziam; seja num artefato para a guerra, num equipamento para a caça ou a pesca, seja num objeto para o uso doméstico, a preocupação com a beleza se faz presente o tempo todo. Ribeiro (2008, p. 66) se refere a esta qualidade artística dos nativos da seguinte maneira:

Na vida indígena o que se vê nas coisas mais simples é esta alegria de viver, esta vontade de beleza expressa de mil modos, por gente comum, que tem um contentamento que entre nós só é dado ao artista criador ou ao apreciador mais sofisticado das nossas altas artes inacessíveis ao homem comum. Lá, a criatividade está generalizada.

Darcy Ribeiro foi um dedicado estudioso e pesquisador da cultura e da vida cotidiana dos povos nativos brasileiros. Ele sintetiza suas 
pesquisas fazendo uma análise da indissociação entre trabalho e lazer, entre arte e técnica. Assim, refere-se ao que acontece na relação cotidiana dos povos nativos com o que denominamos, em nossa cultura ocidental contemporânea, de arte e de beleza.

\begin{abstract}
É impensável deixar de ver a perfeição formal de uma panela, de uma peneira, de uma casa ou de um colar. Um corpo pintado com urucum para uma tarde de festa é uma obra de arte feita com o zelo com que um pintor pinta uma tela. Uma perfeição perfeitamente inútil, se poderia dizer. Mas a beleza á precisamente isso, é uma perfeição perfeitamente inútil que esquenta o coração e dá alegria. (Ribeiro, 2008, p. 67).
\end{abstract}

Percebe-se que os indígenas compreendem o sentido da cadeia da vida, do fluir do viver, dessas coordenações consensuais de que tanto fala Maturana (1999): "um sistema de conversação é, portanto, um sistema não linear que não se rege por uma linearidade causa-efeito, mas o efeito rebate sobre a causa criando um sistema fechado que se autoalimenta". Para os indígenas, assim como para Maturana, a questão fundamental é de como as coisas chegaram a ser o que são, e não sua essência.

Mas não é apenas nas artes que as civilizações indígenas se destacaram e deixaram grandes legados, na técnica também foram muito criativas e sofisticadas - é o caso das técnicas de domesticação de plantas selvagens que desenvolveram e com as quais acrescentavam uma dieta rica e farta a sua subsistência. Não é demais frisar que entre os povos nativos, antes da chegada dos colonizadores europeus, não existiam nem obesidade e muito menos desnutrição. É da responsabilidade deles a introdução nos hábitos alimentares brasileiros da mandioca, do amendoim, do abacaxi, da batata chamada de "batata inglesa", do milho, da batata doce, do inhame e de muitas outras espécies que até os dias de hoje fazem parte de nosso cardápio rotineiro. Darcy Ribeiro ressalta, com muita propriedade, que, mesmo hoje, com toda nossa sofisticada tecnologia, inclusive de engenharia genética, ainda não domesticamos nenhuma outra planta além daquelas que os nativos deixaram para nós como alternativa de alimento. Assim, o autor finaliza sua defesa da sofisticação da forma de vida dos povos nativos: "contando com estas fontes de provimento, através do trabalho coletivo, os índios viviam uma vida farta em que ninguém era pobre demais para não ter casa e comida, nem rico demais para que lhe sobrasse o que faltava a outro" (Ribeiro, 2008, p. 60).

Para encerrar este tópico, deixamos uma segunda sugestão para pensar-se uma pedagogia e uma educação junto às comunidades indígenas.

Diferentemente de nossa escola tradicional em que tudo é separado em disciplinas e os momentos são demarcados segundo uma lógica própria da cultura ocidental, na educação junto aos povos indígenas há que se rever com radicalidade essa perspectiva, a qual, diga-se de passagem, nem mesmo em nossas escolas de educação regular tem dado resultados que nos satisfaçam. Uma comprovação dessa inadequação é o fato de termos ainda que conviver com índices inaceitáveis de analfabetismo, abandono da escola, repetência, baixos índices de aprendizagem, etc. 


\title{
Educação escolar indígena inclusiva: do cuidado de si ao cuidado do outro
}

\begin{abstract}
Uma criança que cresce no respeito por si mesma pode aprender qualquer coisa e adquirir qualquer habilidade se o desejar. (Maturana, 2002, p. 12).
\end{abstract}

Algumas expressões de tanto serem usadas acabaram se transformando em um bordão que dificulta o pensar-se uma escola que possa contemplar as necessidades culturais dos povos indígenas. Para Bergamaschi (2009), uma dessas expressões é: "é muito difícil fazer uma escola diferenciada", quando se pensa na educação escolar indígena.

Sem dúvida que pensar uma escola que possa acolher os saberes e os fazeres dos povos indígenas e, ao mesmo tempo, consiga contemplar aquilo que um currículo e uma organização escolar tradicional, do mundo ocidental, determinam como mínimo a ser considerado para os diferentes níveis de escolarização, é um grande desafio pedagógico e epistemológico.

Em nosso entendimento, uma das maneiras de enfrentarmos esse desafio e avançarmos é, justamente, buscando interlocuções com ideias e proposições epistemológicas que enfatizem o diálogo intercultural, o cuidado com o outro e a escuta sensível daquilo que perpassa os processos relacionais nas comunidades de aprendizagem. Ao refletir sobre esse desafio, Bergamaschi (2009, p. 182) assim se manifesta e nos dá uma pista possível a ser seguida:

\begin{abstract}
É no fazer diário, marcado pela cosmologia indígena, que se faz uma escola diferenciada, nos pequenos, porém, potentes indícios que apontem um outro modo de fazer escola. Nessa perspectiva, os sentidos da escola vão se constituindo em atos ao apropriarem-se de um aparelho educativo que não nasceu no interior de suas antigas tradições, mas que, ao trazê-lo para dentro da aldeia, conferem-lhe significados próprios.
\end{abstract}

Ao propormos o cuidado e a escuta como princípios epistemológicos para pensar-se uma educação escolar junto às comunidades indígenas, estamos, concretamente, buscando criar um espaço de convivência escolar que possa abrigar não só as diferenças entre a cultura indígena e a ocidental, como também incentivar uma relação de reciprocidade intercultural de aprendizagens comuns e, com isso, a inclusão educacional e social. Não podemos esquecer que uma questão fundamental para o acolhimento daqueles que chegam à escola é que recebam uma atenção que respeite o fluir de seu viver original. Isso não significa a pura e simples acomodação às diferenças, mas tem a ver com a criação de um espaço em que possam ser mediados os conflitos inter-étnico-culturais, tendo como ponto de partida a resolução pacífica deles. Dessa forma, estamos sugerindo uma escola que venha ao encontro do sentido que educandos possam atribuir a ela. Esses sentidos não serão, certamente em muitos casos, os mesmos que os gestores e professores estão habituados a conferir à escola. 
Nessa perspectiva de pensar e organizar um espaço escolar de caráter intercultural e inclusivo, sugerimos levar-se em conta o que Maturana (2002, p. 13) propõe como um dos papéis fundamentais da escola:

A tarefa da educação escolar é permitir e facilitar o crescimento das crianças como seres humanos que respeitem a si próprios e os outros com consciência social e ecológica, de modo que possam atuar com responsabilidade e liberdade na comunidade a que pertencem.

Para o autor, o conhecimento é uma construção da linguagem criada nas relações de afeto e carinho que, por sua vez, são emocionadas, como já havíamos mencionado anteriormente. Nas palavras de Maturana (1998a, p. 23), "o educar se constitui no processo em que a criança ou o adulto convive com o outro e, ao conviver com o outro, se transforma espontaneamente de maneira que seu modo de viver se faz, progressivamente, mais congruente com o outro no espaço da convivência". É em função disso que, para esse autor, uma criança que cresce no respeito por si mesma pode aprender qualquer coisa e adquirir qualquer habilidade se o desejar, por exemplo, quando Maturana coloca que os seres humanos são constituídos por meio da linguagem, que o ser humano tem necessidade contínua de se autocriar, e isso faz com que linguagem e cognição, mediante ações efetivas, estejam sempre se constituindo socialmente em redes de conversações que configuram nosso mundo.

Também para os indígenas, todos os processos de aprendizagem se dão à medida que cada criança ou adulto se desenvolve por si só dentro de um conjunto de relações com os outros, sendo autônomos, mas pensando num bem maior. Suas práticas educativas oportunizam a consciência de se ver como membro de um todo, integrantes e criadores. Esse conviver com o outro, implicando uma transformação espontânea, existe na medida em que ocorre a aceitação do outro como legítimo em sua diferença, ou seja, na abertura para alteridade e na abdicação de ações coercitivas e de dominação.

Dessa forma, percebemos que tanto para os indígenas quanto para Maturana o educar deixa de ser entendido como um ato da fala, enquanto apresentação de quem domina certas informações pronunciadas como verdades, e passa a constituir-se em comunicação de sistemas viventes nas ações comuns: "como vivemos é como educaremos, e conservaremos no viver o mundo que vivemos como educandos. E educaremos outros com nosso viver com eles, o mundo que vivermos no conviver." (Maturana, 1999, p. 30). Assim vista, a educação deveria ser parte essencial da humanização de homens e mulheres e não uma desintegração de valores; uma simetria inversa. A educação pode ajudar o ser humano a cumprir sua vocação ontológica e, para isso, é necessário que cada um seja ator/ autor de sua história. Arroyo (2000, p. 48), nesse sentido, também contribui, ao escrever que

os professores devem ser capazes de trabalhar em ambientes escolares que possam tornar-se centros de conhecimento coletivo e de solidariedade. Devem estar preparados para compreender a importância de um discurso democrático e as contradições da diversidade cultural. 
Este olhar ao diferente se dá desde o lugar de onde estamos e somos. Então, essas diferenças que se chocam com a cultura indígena poderiam parecer, à primeira impressão, um desvio aos nossos "olhos ocidentais" de ver o mundo, num desencontro de costumes. Nessa mesma direção, é importante o que sugere Fleuri (2004, p. 417), quando afirma que, para além de uma compreensão rígida, disciplinar e normatizadora da diversidade das culturas, "emerge o campo híbrido, fluido, polissêmico, ao mesmo tempo trágico e promissor da diferença, que se constitui nos entre-lugares e nos entreolhares das enunciações de diferentes sujeitos e identidades socioculturais".

É nesse sentido que Maturana define a vida como um processo permanente de conhecimento, identificando o viver com o conhecer. Sua teoria da cognição, conhecida como Biologia da Cognição ou como Teoria de Santiago, coloca os seres vivos como co-construtores do mundo, seres em constante processo de aprendizagem, condição essencial para a conservação da vida. Assim, construímos o mundo na interação com o outro, o influenciamos e modificamos na mesma medida em que somos, também, modificados e influenciados.

Desse modo, Maturana (1995, p. 15) nos deixa a seguinte e desafiadora questão:

Não nascemos nem amando nem odiando ninguém em particular. Como então aprendemos isso? Como o ser humano é capaz de odiar com tanta virulência, a ponto de destruir os outros, mesmo à custa de sua própria destruição na tentativa? Ele começa a aprender isso já na sua própria família?

Com essa pergunta, parece-nos que fica evidente que a intenção de Maturana é mostrar que nossas atitudes refletem aquilo que estamos vivendo na relação com o outro, e que esta, por sua vez, é definida pela emoção que orienta tais atitudes. Outro aspecto importante a destacar na educação indígena é o espaço ritualístico de educação, onde as crianças são educadas num mundo espiritual e sagrado, dentro de uma relação de confiança e respeito pelos demais. Segundo Toro (2008), os sentimentos produzidos a partir da vitalidade são de alegria e entusiasmo, os quais geram como evolução humana a experiência de autonomia e êxtase, desencadeando sentimentos de ternura, amizade e amor.

A aprendizagem nas comunidades indígenas, aqui tomamos o exemplo Guarani, dá-se mediante a troca de experiências, na construção de um saber coletivo, intermediada pelo karaí/professor - a confirmação dessa troca é feita pela transmissão do conhecimento coletivo, sendo que para isso o docente necessita de aprendizes que garantirão o diálogo de seus conhecimentos e sua transformação como pessoa. Assim, o papel do karaí, enquanto educador, é o de mobilizar essa aprendizagem que se dá num processo contínuo, numa perspectiva de que se aprende na convivência com o outro. A valorização do conhecimento parte do autoconhecimento, ou seja, da capacidade de vivenciar o que se fala e de que a fala seja a expressão do que se sente, pois, como escreve Menezes (2008, 
p. 71), o saber do povo guarani "torna-se conhecimento ou o conhecer transforma-se em sabedoria quando este aprende a arte de compartilhar as experiências, os sentimentos. A reflexão é o ato de expressar e de escutar as emoções por meio dos sentidos".

Portanto, educar é fazer a palavra em movimento, fazer verbo, enquanto ações cheias de sentido, vivência e conhecimentos aprendidos ao longo de toda a vida. Assim, exprime-se e define o papel importante do karaí: corpo vivido que busca continuamente o aprendizado de constituir-se singular na vivência coletiva do compartilhar.

Percebe-se, com isso, que existe uma metodologia de ensino Guarani que se coaduna com as reflexões feitas por Arroyo, segundo Menezes (2008, p. 61), com relação às necessidades de nossa pedagogia, ou seja, o respeito ao ciclo-tempo de vida, de forma que os conteúdos trabalhados possibilitem uma construção coletiva de conhecimentos.

Portanto, se a educação acontecer num espaço de amorosidade, em que o emocionar do cuidado e da escuta do outro esteja interligado ao fazer pedagógico, nossas práticas pedagógicas fluirão na liberdade de escolhas e reflexões sobre o que queremos e podemos, sobre o que somos e sobre as coisas que nos sucedem. Nessa valorização de experiências, os professores entenderão melhor o prazer da convivência, da ternura e do cuidado com os outros, em especial com os educandos.

Acreditamos que, dessa relação de escuta e de cuidado com o outro, teremos grandes possibilidades de ver acontecer um processo de inclusão que não se restrinja apenas a formalidade da legislação e ao desejo generoso de justiça, mas que aconteça realmente no fluir do viver no cotidiano escolar.

Com isso, estamos exercitando e vivenciando o fato de que o humano não nasce pronto, ele está em constante formação, e não só tem a capacidade de aprender a ser, como também tem a necessidade de aprender a ser humano. Isso só é possível na interação e no relacionamento com os outros por meio de processos interculturais mediados pela linguagem e pelo diálogo. Esse processo de mediação dialógica se constituirá em solo fértil para a inclusão quando tivermos uma ação pedagógica e uma educação escolar indígena pautadas, fundamentalmente, na escuta sensível do outro e no cuidado para com suas especificidades históricas e culturais.

\section{Referências bibliográficas}

ARROYO, Miguel Gonzalez. Ofício de mestre: imagens e auto-imagens. Petrópolis, RJ: Vozes, 2000.

BATESON, Gregory. Mente e natureza: a unidade necessária. Rio de Janeiro: Francisco Alves, 1986.

BERGAMASCHI, Maria Aparecida. Educação indígena em diálogo na UFRGS: um sonho possível. In: BORGES, Juçara de Fátima; SANTOS, 
Simone Valdete dos; MARQUES, Tânia Beatriz Iwasko (Org.). Educação indígena em diálogo. Pelotas: Edufpel, 2011.

BERGAMASCHI, Maria Aparecida; MENEZES, Ana Luisa Teixeira de. Educação ameríndia: a dança e a escola guarani. Santa Cruz do Sul: Edunisc, 2009.

BHABHA, Homi. O local da cultura. Belo Horizonte: Ed. UFMG, 2003.

BRASIL. Lei no 9. 394, de 20 de dezembro de 1996. Estabelece as diretrizes e bases da educação nacional. Diário Oficial União, Brasília, DF, 23 dez. 1996. Disponível em: <http://www.planalto.gov.br/ ccivil_03/LEIS/L9394.htm>.

CANCLINI, Néstor Garcia. Consumidores e cidadãos: conflitos multiculturais da globalização. Rio de Janeiro: UFRJ, 2006.

. Culturas híbridas. São Paulo: EDUSP, 2003. Diferentes, desiguales y desconectados: mapas de la interculturalidad. Barcelona: GEDISA, 2004.

CLAUDINO, K. Z. Educação escolar indígena: um sonho possível. In: BORGES, Juçara de Fátima; SANTOS, Simone Valdete dos; MARQUES, Tânia Beatriz Iwasko (Org.). Educação indígena em diálogo. Pelotas: Edufpel, 2011.

FIGUEIREDO, J. B. Educação e afetividade na relação com o outro: contribuições da perspectiva eco-relacional. In: BARCELOS, V.; ROSSATO, R.; HENZ. C. Educação humanizadora e os desafios da diversidade. Santa Cruz do Sul: Edunisc, 2008.

FLEURI, R. M. Educação intercultural: desconstrução de subalternidades em práticas educativas e socioculturais. Florianópolis: UFSC, CNPq, 2007. (Projeto Integrado de Pesquisa, processo CNPq 301810/2006-0, vigência 2007-2010).

. Rebeldia e democracia na escola. Revista Brasileira de Educação, ANPEd, Campinas, SP, v. 3, n. 23, 2004.

. Intercultura e educação. Revista Brasileira de Educação,

Anped, Campinas, SP, n. 23, 2003.

. Intercultura e movimentos sociais. Florianópolis: NUP, UFSC, 1998.

FREIRE, Paulo. Ação cultural para a liberdade. São Paulo: Paz e Terra, 2002 . 
FREIRE, Paulo. Pedagogia da indignação: cartas pedagógicas e outros escritos. São Paulo: Unesp, 2000.

GONÇALVES, C. W. P. A globalização da natureza e a natureza da globalização. Rio de Janeiro: Civilização Brasileira, 2006.

MATURANA, Humberto. Cognição, ciência e vida cotidiana. Belo Horizonte: UFMG, 2001. Emoções e linguagem na educação e na política. Belo Horizonte: UFMG, 1999.

. Emoções e linguagem na educação e na política. Belo Horizonte: UFMG, 1998a.

. Da biologia à psicologia. Porto Alegre: Artes Médicas, 1998b.

. Reflexões sobre o amor. In: MAGRO, C.; GRACIANO, M.; VAZ, N. (Org.). A ontologia da realidade. Belo Horizonte: UFMG, 1997.

. De máquinas e seres vivos: autopoiese, a organização dos seres vivos. Porto Alegre: Artes Médicas, 1997.

MATURANA, H. R.; DÁVILA, X. Educación desde la matriz biológica de la existencia humana: biología del conocer y biología del amar. Chile, 2005. Disponível em: http://72.14.209.104/ search?q=cache:JIESOSL8u60J:www.unesco.cl/medios/ biblioteca/documentos/sentidos_educacion_ponencia_humberto_ maturana_ximena_davila.pdf+www. + unesco.cl/medios/biblioteca/ documentos/+sentidos_educacion_ponencia_humberto_maturana_ ximena_davila.pdf $+-\& h \mathrm{l}=\mathrm{es} \& \mathrm{ct}=\mathrm{clnk} \& \mathrm{~cd}=1 \& \mathrm{lr}=$ lang_es. Acesso em: 19 set. 2011.

MATURANA, H.; REZEPEKA, N. S. Formação humana e capacitação. Petrópolis: Vozes, 2002.

MATURANA, H. R.; VARELA, F. G. A árvore do conhecimento: as bases biológicas do conhecimento humano. Campinas, SP: Workshop, 1995.

MATURANA, R. M.; VERDEN-ZÖLLER, G. Amar e brincar: fundamentos esquecidos do humano. São Paulo: Palas Athena, 2004.

MENEZES, Ana Luísa T. Educação guarani: compartilhando saberes, construindo conhecimento. In: BERGAMASCHI, M. A. (Org.). Povos indígenas e educação. Porto Alegre: Mediação, 2008. Cap. 4.

RIBEIRO, Darcy. Utopia Brasil. São Paulo: Hedra, 2008. 
SANTIAGO, Silviano. Ora (direis) puxar conversa: ensaios literários.

Belo Horizonte: UFMG, 2006.

. Uma literatura nos trópicos. Rio de Janeiro: Rocco, 2000.

THOMPSON, W. I. Gaia: uma teoria do conhecimento. São Paulo: Gaia, 1990.

TORO, R. A. Biodança. São Paulo: Olavobrás, 2008.

WEBER, Cátia. Educação escolar e os povos indígenas. Florianópolis:

NUP, UFSC, 2009.

Valdo Hermes de Lima Barcelos, doutor em Educação pela Universidade Federal de Santa Catarina (UFSC), é professor adjunto no Departamento de Administração Escolar da Universidade Federal de Santa Maria (UFSM) e no Programa de Pós-Graduação da Educação da UFSM, na linha de Formação, Saberes e Desenvolvimento Profissional.

vbarcelos@terra.com.br

Sandra Maders, mestranda em Educação no Programa de Pós-Graduação da Educação da Universidade Federal de Santa Maria (UFSM), é professora de Educação Infantil e pesquisadora do Núcleo Kitanda: Educação e Intercultura, CNPq-UFSM. Desenvolve Pesquisas sobre a obra de Humberto Maturana e sobre formação de professores para educação escolar indígena.

sandrinhamaders@hotmail.com

Recebido em 19 de abril de 2011.

Aprovado em 21 de dezembro de 2011. 